\title{
Gut microbiome of endangered Tor putitora (Ham.) as a reservoir of antibiotic resistance genes and pathogens associated with fish health
}

Himani Khurana ${ }^{1,2}$, Durgesh Narain Singh ${ }^{2,3}$, Anoop Singh ${ }^{3}$, Yogendra Singh ${ }^{3}$, Rup Lal $^{2,4^{*}}$ and Ram Krishan Negi ${ }^{1^{*}}$ (D)

\begin{abstract}
Background: Tor putitora, the largest freshwater fish of the Indian subcontinent, is an endangered species. Several factors have been attributed towards its continuous population decrease, but very little is known about the gut microbiome of this fish. Also, the fish gut microbiome serves as a reservoir of virulence factors and antibiotic resistance determinants. Therefore, the shotgun metagenomic approach was employed to investigate the taxonomic composition and functional potential of microbial communities present in the gut of Tor putitora, as well as the detection of virulence and antibiotic resistance genes in the microbiome.

Results: The analysis of bacterial diversity showed that Proteobacteria was predominant phylum, followed by Chloroflexi, Bacteroidetes, and Actinobacteria. Within Proteobacteria, Aeromonas and Caulobacter were chiefly present; also, Klebsiella, Escherichia, and plant symbionts were noticeably detected. Functional characterization of gut microbes endowed the virulence determinants, while surveillance of antibiotic resistance genes showed the dominance of $\beta$-lactamase variants. The antibiotic-resistant Klebsiella pneumoniae and Escherichia coli pathovars were also detected. Microbial genome reconstruction and comparative genomics confirmed the presence of Aeromonads, the predominant fish pathogens.

Conclusions: Gut microbiome of endangered Tor putitora consisted of both commensals and opportunistic pathogens, implying that factors adversely affecting the non-pathogenic population would allow colonization and proliferation of pathogens causing diseased state in asymptomatic Tor putitora. The presence of virulence factors and antibiotic resistance genes suggested the potential risk of dissemination to other bacteria due to horizontal gene transfer, thereby posing a threat to fish and human health. The preservation of healthy gut microflora and limited use of antibiotics are some of the prerequisites for the conservation of this imperilled species.
\end{abstract}

Keywords: Gut microbiome, Endangered Tor putitora, Virulence genes, Antibiotic resistance genes, Opportunistic pathogens

\footnotetext{
*Correspondence: ruplal@gmail.com; negi_gkv@rediffmail.com

${ }^{2}$ Molecular Biology Laboratory, Department of Zoology, University of Delhi, Delhi 110007, India

${ }^{1}$ Fish Molecular Biology Laboratory, Department of Zoology, University of Delhi, Delhi 110007, India

Full list of author information is available at the end of the article
}

(c) The Author(s). 2020 Open Access This article is licensed under a Creative Commons Attribution 4.0 International License, which permits use, sharing, adaptation, distribution and reproduction in any medium or format, as long as you give appropriate credit to the original author(s) and the source, provide a link to the Creative Commons licence, and indicate if changes were made. The images or other third party material in this article are included in the article's Creative Commons. licence, unless indicated otherwise in a credit line to the material. If material is not included in the article's Creative Commons licence and your intended use is not permitted by statutory regulation or exceeds the permitted use, you will need to obtain permission directly from the copyright holder. To view a copy of this licence, visit http://creativecommons.org/licenses/by/4.0/. The Creative Commons Public Domain Dedication waiver (http://creativecommons.org/publicdomain/zero/1.0/) applies to the data made available in this article, unless otherwise stated in a credit line to the data. 


\section{Background}

The gastrointestinal tract is a complex environment inhabited by diverse groups of microbial communities [1-3]. The gut bacteria play an important role in maintaining the normal physiology, nutrition, health, homeostasis, protection against pathogens, and functioning of the host immune system [2, 4-7]. There has been a growing interest in understanding the composition of symbiotic and pathogenic bacteria in the gut [6]. The symbiotic bacteria present in the gut provide several benefits to their hosts, such as digestion of complex indigestible food materials, production of important secondary metabolites, and defence against pathogens $[2$, 7-10], several opportunistic bacterial pathogens are also reported in the gut microbial community [11, 12]. Alterations in normal gut microflora reduce the competition for pathogens and result in their overgrowth leading to the diseased state [13]. Microbial dysbiosis causes impairment of the normal activity of digestive enzymes, damage to gut tissue, and increased infiltration of opportunistic pathogens and toxicants [14]. This fact has drawn considerable attention to find out potential probiotic, symbiotic, and pathogenic bacteria that may have a profound influence on the host physiology and health. While there are several studies on the fish gut microbiome, hitherto, there are gaps in our understanding on the structure and function of the gut microbiome in endangered fish $[1,2,15,16]$.

Most of the knowledge with respect to the fish gut microbiome was based on the use of culture-based methods for the investigation of microbial communities $[6,17]$. However, culture-independent methods allow identification of a large proportion of microbial diversity than could be observed with culture-based studies [18]. Although 16S rRNA (marker-gene) sequencing provides information about the taxonomic composition of microbial communities, it provides limited information about their functional capabilities and metabolic pathways [19]. On the other hand, whole genome shotgun metagenomics can overcome these caveats and allow for a deeper understanding of the gut microbial communities and host-microbiota interactions [19-21]. The composition of microbial communities residing in the intestinal tract of different fish showed the presence of both beneficial and pathogenic microbes [2, 22-25]. However, it remains a challenge to elucidate whether the gut microflora drives for protection (friends) or disease development (foes) in fish. The fish gut is natural reservoir of Aeromonas, Pseudomonas, Vibrio, Streptococcus, and other coliforms [26-30]. The presence of virulence genes and antibiotic-resistance genes in Aeromonas spp. from freshwater may also be responsible for causing infections in humans as there have been reports of transmission of infectious Aeromonas from fish following injuries during handling, practicing aquaculture systems or pet fish keeping [31-34]. Aeromonads, the predominant species associated with the gastrointestinal tract of aquatic animals, are known to cause a multitude of diseases in freshwater fish [7, 30, 35, 36]. Among all the Aeromonads, Aeromonas veronii has the greatest range in virulence and has been associated with infectious abdominal dropsy in fish [37]. Also, there have been reports on the presence/transmission of opportunistic and other pathogenic bacteria in fish, making them potential carriers [26, 27, 29, 38-41]. Thus, it is imperative to detect virulence genes in the microbiome of fish for their possible transmission.

The aquaculture sector is a major contributor to the world's production for food [22]. Overuse of antibiotics in aquaculture has led to the rapid emergence of antibiotic resistance genes (ARGs) in the aquatic environment where fish serve as a reservoir of multidrugresistant bacteria and their potential mobilization [19, 42-44]. The dissemination of antibiotic resistance genes from fish bacteria to human pathogens is a serious threat to public health $[43,44]$. Surveillance of ARGs in fish would aid in the development of regulations for the application of antibiotics in aquaculture.

Tor putitora (Ham.) is commonly known as golden mahseer due to its large size, attractive golden colour and sport values. It has been promoted as a 'flagship' species of the Indian subcontinent $[45,46]$ and has been enlisted endangered by International Union for Conservation of Nature (2010) and IUCN Red List assessment [47]. It is widely distributed in Afghanistan, Bangladesh, Bhutan, Myanmar, Nepal, Pakistan, and in India, its distributional range is in the Northeast Himalaya which includes Himalayan foothills, Garo hills of Meghalaya and Challou river of Manipur [45]. It is an indigenous fish species and forms mainstay fishery of upland Himalayan region [48]. It is consumed by people because it contains high-quality proteins making it a potential resource for aquaculture industries. Besides this, it is also a good source of minerals acting as diet supplements [48]. Tor putitora is an economically important fish because it has great culinary value, forms lucrative sport fishery in the Himalayan river, and provides employment opportunities to locals [49]. Despite this, very limited research efforts have been made to investigate the commensal/beneficial/pathogenic bacteria in the gut of this fish species [39]. In India, the Gobindsagar reservoir $\left(31^{\circ} 24^{\prime} 59.99^{\prime \prime} \mathrm{N}, 76^{\circ} 29^{\prime} 59.99^{\prime \prime} \mathrm{E}\right)$ is one of the largest man-made lakes which port Tor putitora [50]. Mahseer used to constitute as high as $9 \%$ of the total catch during 1984-85, which has decreased rapidly to $1 \%$ during 1999-2000 [50]. Therefore, the major objective of this study was to understand the taxonomic composition and functions of bacterial communities associated with the 
gut of Tor putitora. The second focus of this study was to understand the antibiotic resistance pattern of gut bacterial communities.

\section{Results}

Taxonomic composition of fish gut microbiome

The Illumina HiSeq 2500 platform generated a total of $284,412,950$ paired-end reads, $n=120,716,302$ pairedend reads in fish gut metagenome 1 (FGM1) and $n=$ $163,696,648$ paired-end reads in fish gut metagenome 2 (FGM2) yielding total 71.3 gigabase high-quality whole metagenome shotgun sequence data. The final merged read length was $200 \mathrm{bp}$. The other details regarding sequencing and assembly have been mentioned in Additional file 1: Table S1. The values of Shannon-Wiener index (H) 1.796 (FGM1) and 2.362 (FGM2) as well Simpson's index value (1-D) of 0.7998 (FGM1) and 0.8792 (FGM2) depicted compositional shift in the microbial diversity of gut of Tor putitora. The rarefaction curves based on alpha diversity measures depicted the saturation phase at $1 \mathrm{e}+06 \mathrm{bp}$ sequencing effort (Additional file 2: Figure S1). Likewise, beta diversity analysis was conducted to determine the similarity or dissimilarity in the composition of microbial communities of the samples. The Non-metric Multi-Dimensional Scaling (NMDS) plot based on the Whittaker index explained variance in the diversity of the two samples (Additional file 2: Figure S2). Similarly, pairwise correlations computed using Pearson's method $\left(R^{2}=0.7947\right)$ depicted a positive correlation between microbial communities of two metagenomes. The microbial community was dominated by bacteria $(97.07 \%)$, whereas the abundance of viruses $(0.37 \%)$ and archaea $(0.02 \%)$ was relatively low. Within bacteria, FGM1 and FGM2 were dominated by $95.96 \%$ and $91.33 \%$ Proteobacteria, respectively. Besides, Chloroflexi, Actinobacteria, and Bacteroidetes were also present (Fig. 1a). The relative abundance at genera level depicted that FGM1 was dominated by Caulobacter (28.62\%), Aeromonas (28.18\%), Klebsiella (12.4\%), Escherichia (10.1\%), Bradyrhizobium (9.55\%) and Mesorhizobium (3.81\%). Likewise, FGM2 microbial community comprised Aeromonas (24.51\%), Pseudomonas (12.06\%), Caulobacter (11.59\%), Klebsiella (10.08\%), Bradyrhizobium (9.12\%), Escherichia (7.34\%) and Mesorhizobium (0.68\%). Moreover, Rhodopseudomonas, Mycobacterium, Vibrio, and Methylobacterium were also detected (Fig. 1b). Members of Aurantimonadaceae, Acetobacteraceae, and Sphingobacteriaceae could not be classified to the genus. The relative abundance of different species is illustrated in Fig. 1c.

Functional characterization of gut microbial communities In this study, both the KEGG and SEED databases were used to predict the metabolic potential of the gut microbiome. The KEGG pathway analysis using Pearson's correlation and hierarchical clustering showed a higher relative abundance of pathways involved in metabolism (28.7\% in FGM1, 28.9\% in FGM2), followed by biosynthetic pathways (15.6\% in FGM1, $12.06 \%$ in FGM2) and pathways for degradation (12.22\% in FGM1 and $11.66 \%$ in FGM2). In the pathways for metabolism, vitamin B6 metabolism, nucleotide sugars, and alanine and aspartate metabolism were dominant. Under the category for biosynthesis, pathways for lipopolysaccharide biosynthesis, peptidoglycan biosynthesis, and antibiotic production were abundant. Discounting core metabolism and energy, several pathogenesis-related genetic traits, including bacterial chemotaxis, flagellar assembly, and type III secretion system, were also present (Fig. 2a). Moreover, pathways of type II- and type IV secretion systems, $\beta$-lactam resistance, and Vibrio cholerae pathogenic cycle was also detected (Fig. 2a). The functional assignment of normalized reads in the metagenomes with SEED database also revealed similar patterns with maximum reads assigned to the cofactors, vitamins, prosthetic groups, pigments, protein metabolism, fatty acids, lipids, and isoprenoids and metabolism of aromatic compounds. The pathways for cell wall and capsule formation, iron acquisition and metabolism, virulence, motility and chemotaxis, phages, prophages, transposable elements, plasmids showed high relative abundance in both the metagenomes. All these pathways were significantly different (Fisher's exact test at 0.95 confidence interval, $p$-value $<0.05$ ) among the metagenomes (Fig. 2b).

\section{Detection of virulence genes in the fish gut microbiome}

Fish gut microbiome could be a possible reservoir of virulence genes and resistance determinants; therefore, the gut metagenome was explored for genes encoding virulence factors of putative pathogens in fish. Search against Aeromonas virulence factor database depicted the presence of a total of 157 virulence genes. The key virulence factor of Aeromonas salmonicida is type III secretion system (TTSS) which is present on a large-sized plasmid encoded by different genes arranged in five major polycistronic operons (i) exs $A, D$, asc $B, C, D, E, F, G, H$, $I, J, K, L$ (ii) exs $C, E, B$ (iii) aopN, acr1,2, asc $X, Y, V, a c r R, G, V, H$, $a o p B, D$ (iv) $a s c N, O, P, Q, R, S, T, U$ and (v) $\operatorname{aop} X, s y c X$ (Fig. 3a). The Blastp searches against the virulence factor database were performed using the similarity criteria of e-value $<1 \mathrm{e}-5$, percent identity $\geq 80 \%$, alignment length/ subject length $\geq 0.8$, and alignment length/query length $\geq$ 0.8 . Thirty-one genes of a total of 38 genes comprising the TTSS operon of Aeromonas salmonicida were detected (Fig. 3b, Additional file 1: Table S2). Some TTSS genes (ascD, ascE, ascF, ascK, exsB, ascP, and aopX), including aexT, which encodes TTSS effector protein, 


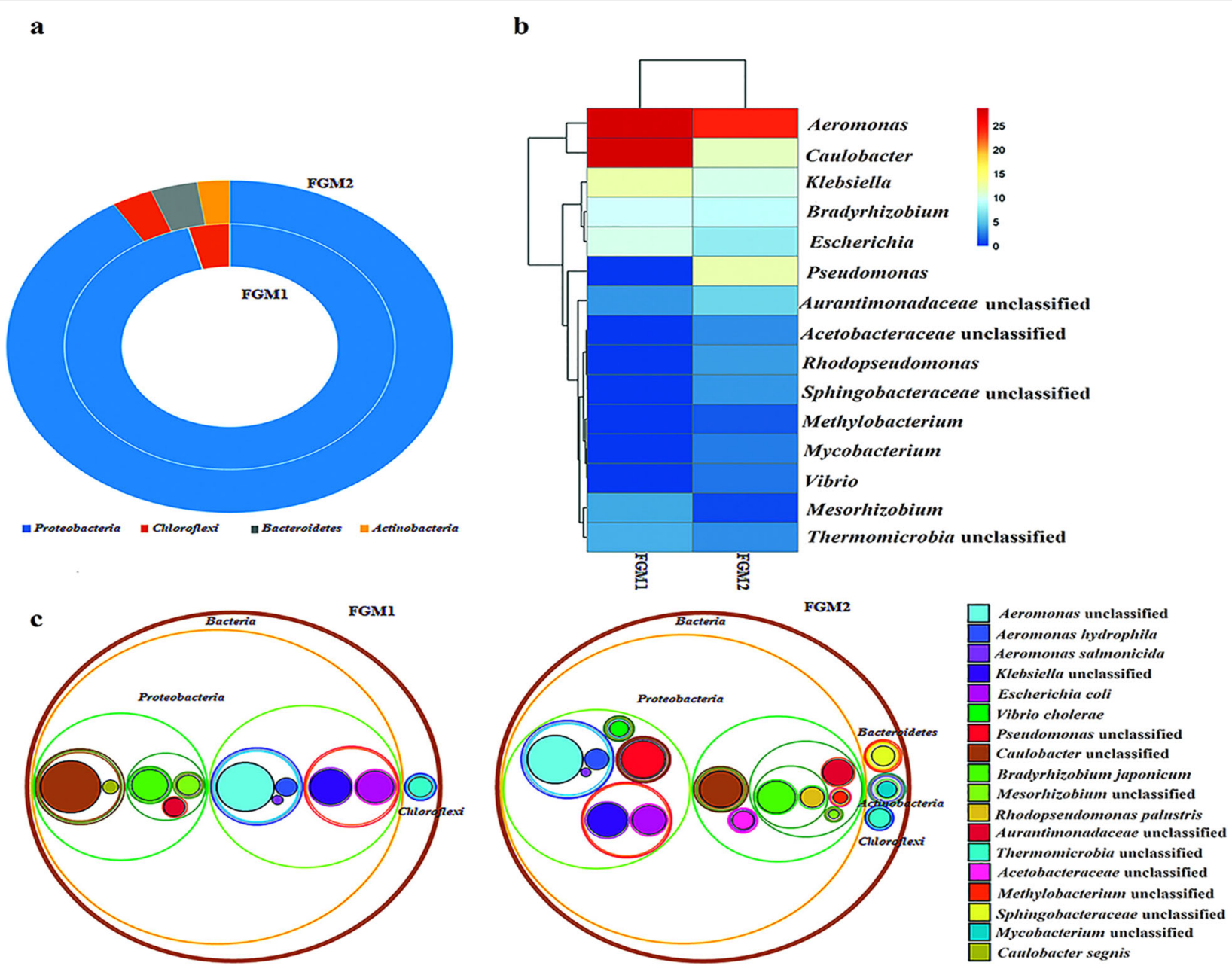

Fig. 1 Composition of gut microbiome in endangered Tor putitora. a Figure showing relative abundance of different phyla in fish gut metagenome. $\mathbf{b}$ The hierarchical clustering in heatmap shows the abundance of different genera enriched in the gut microbial community. 7.34 and $15.27 \%$ of the reads could not be assigned to any genus in FGM1 and FGM2, respectively. c Species-level classification of fish gut microbiome. The diameter of the circle represents the proportion of reads assigned to the particular species. The arrangement of circles represents the hierarchy from kingdom to species level

were detected below the cut-off. Furthermore, genes encoding hemolysin III and thermostable hemolysin in Aeromonas veronii, flagellar apparatus in Aeromonas salmonicida, and Aeromonas hydrophila, and HcpA, effector protein of type VI secretion system in Aeromonas hydrophila were also detected using the same parameters as mentioned above (Additional file 1: Table S2).

Similarly, the search against the Escherichia coli virulence factor database depicted the presence of different virulence genes. With e-value $<1 \mathrm{e}-5$, percent identity $\geq 80 \%$, alignment length/subject length $\geq 0.8$ and alignment length/query length $\geq 0.8$, total 100 genes belonging to different classes of entero-virulent Escherichia coli strains were identified (Additional file 1: Table S3). The relative abundance of virulence genes representing enterohemorrhagic Escherichia coli (EHEC) strains was $46 \%$, followed by $33 \%$ uropathogenic
Escherichia coli (UPEC). The virulence genes associated with enteroinvasive Escherichia coli (EIEC) (9\%), avian pathogenic Escherichia coli (APEC) (8\%), and benign laboratory strain Escherichia coli (BLS) (3\%) were also detected (Fig. 4). Of the total EHEC detected in the metagenomes, the relative abundance of virulence genes associated with enterohemorrhagic Escherichia coli O157:H7 serotype was abundant, whereas those associated with Escherichia coli strain RS218 were least.

The mining of Pseudomonas virulence genes in the fish gut metagenome resulted in the identification of 79 genes at the filter parameters. Among these, the genes for virulence factors related to adherence (45.57\%) and antiphagocytosis $(27.85 \%)$ were abundant. The major genes for adherence included those related to flagellar apparatus, lipopolysaccharide, and type IV pili, and antiphagocytosis was composed of genes for mucoid 


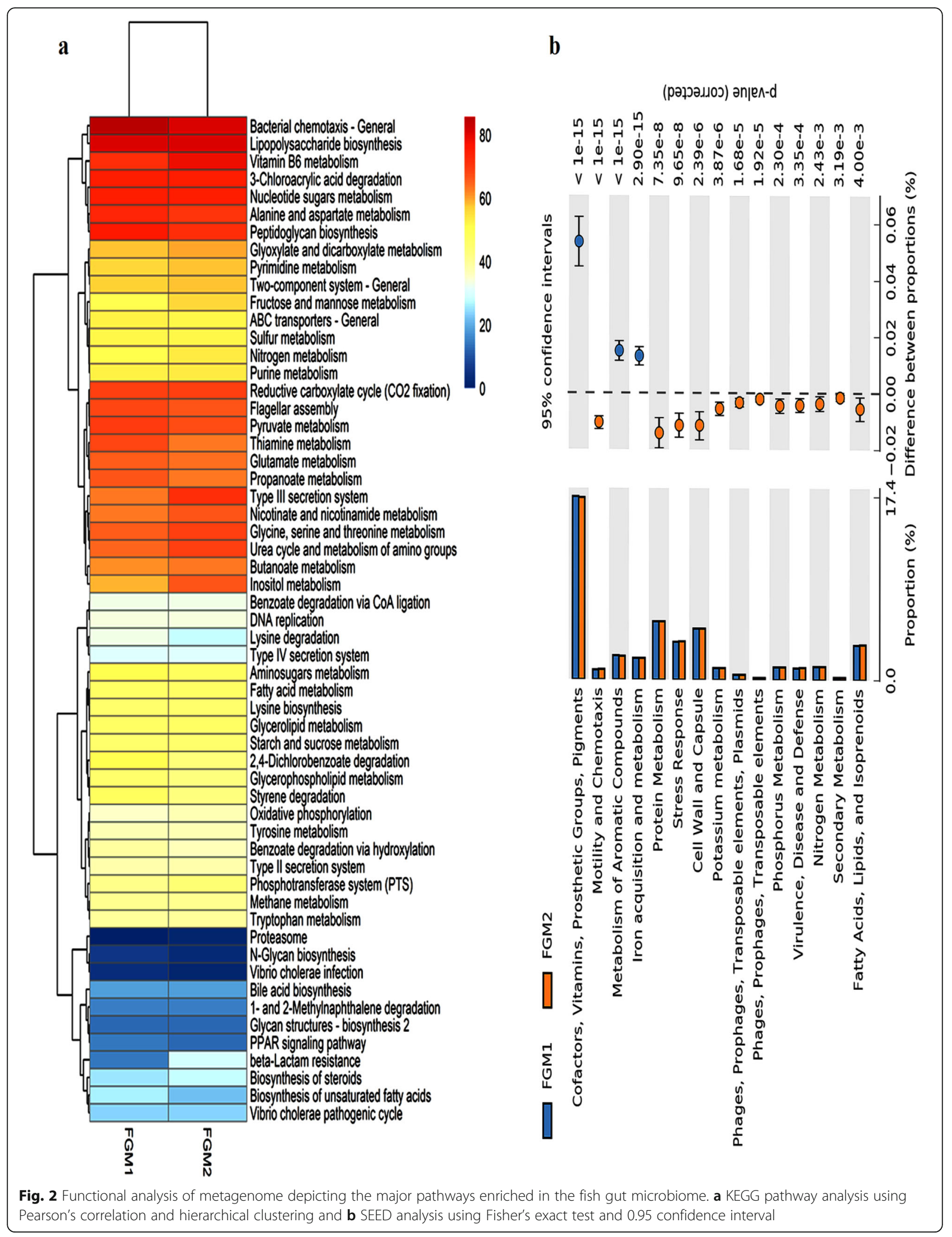



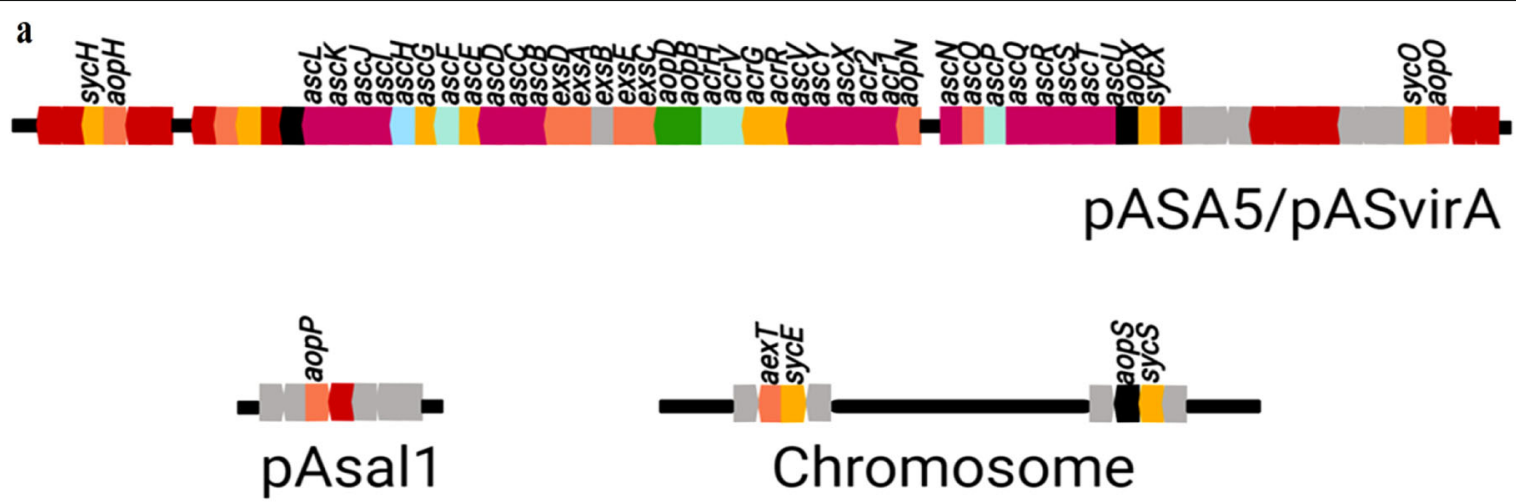

Chromosome

b

\begin{tabular}{|c|c|c|}
\hline TTSS & Function & Genes \\
\hline \multirow[t]{3}{*}{ Translocon } & Pore & $a o p B$ \\
\hline & Pore & aopD \\
\hline & Chaperone & $a c r H$ \\
\hline \multirow[t]{8}{*}{ Needle } & Tip & $a c r V$ \\
\hline & Chaperone & acrG \\
\hline & Body & $a s c F$ \\
\hline & Chaperone & asc $G$ \\
\hline & Chaperone & ascE \\
\hline & Chaperone & $a c r R$ \\
\hline & Polymerization control & asch \\
\hline & Length control & ascP \\
\hline \multirow[t]{16}{*}{ Base } & OM ring & ascC \\
\hline & Chaperone & ascW \\
\hline & Inner rod & ascI \\
\hline & IM ring ext & $a s c D$ \\
\hline & IM ring int & ascJ \\
\hline & C-ring, socket/Cup & $\operatorname{ascR}$ \\
\hline & C-ring, socket/Cup & asch \\
\hline & C-ring, socket/Cup & ascT \\
\hline & C-ring, socket/Cup & $\operatorname{asc} U$ \\
\hline & C-ring, socket/Cup & ascV \\
\hline & C-ring, secretion specificity & $\operatorname{asc} X$ \\
\hline & C-ring, secretion specificity & $\operatorname{asc} Y$ \\
\hline & ATPase & $\operatorname{ascN}$ \\
\hline & Cytoplasmic & ascK \\
\hline & Cytoplasmic & $a s c L$ \\
\hline & Cytoplasmic & $\operatorname{asc} Q$ \\
\hline \multirow[t]{9}{*}{ Regulators } & Secretion & $a \circ p N$ \\
\hline & Secretion & acrl \\
\hline & Secretion & $a s c B$ \\
\hline & Secretion & acr2 \\
\hline & Substrate recycling & $\operatorname{ascO}$ \\
\hline & TTSS transcription & exs $A$ \\
\hline & TTSS transcription & $\operatorname{exs} C$ \\
\hline & TTSS transcription & $\operatorname{exs} D$ \\
\hline & TTSS transcription & exsE \\
\hline \multirow[t]{2}{*}{ Effectors } & ADP-ribosylase+GAP & $\operatorname{aex} T$ \\
\hline & Chaperone & $\operatorname{sycX}$ \\
\hline
\end{tabular}

Fig. 3 (See legend on next page.) 
(See figure on previous page.)

Fig. 3 Type III secretion system in Aeromonas salmonicida. a Genetic organization of type III secretion system (TTSS) genes in Aeromonas salmonicida. TTSS of Aeromonas salmonicida is located on a large plasmid PASA5 and gene encoding effector protein (aexT) is located on the chromosome. At stringent criteria, maximum genes of TTSS were detected while $\operatorname{ascD}$, ascE, ascF, ascK, exsB, asc $P$, and aopX, and aexT were detected below the cut off. $\mathbf{b}$ Genes orthologous of type III secretion system of Aeromonas salmonicida enriched in the fish gut metagenome. Figure modified from: [51]

exopolysaccharide (alginate). Apart from these, genes for TTSS and HSI-I (Hcp1 Secretion Island I) secretion systems were also present. Also, genes encoding for exolysin $(e x l A)$ and iron uptake $(p v d A, p v d S)$ were detected (Additional file 1: Table S4, Additional file 2: Figure S3).

\section{Distribution of antibiotic resistome}

Fish are associated with the dissemination of antimicrobial resistance genes (ARGs). Investigation of antibiotic resistance revealed the presence of a total of 445 ARGs. Primarily, the identified ARGs encoded for $\beta$-lactamases (87.19\%), efflux pumps (5.39\%), multidrug transporters (1.12\%), polymyxins $(0.45 \%)$, vancomycin $(0.22 \%)$ and tetracycline $(0.22 \%)$ resistance (Fig. 5a). In addition, different transcriptional regulators (EvgA, EvgS, GadW) involved in the controlled expression of ARGs were also identified. The relative abundance of $\beta$-lactamase was highest in Klebsiella pneumoniae (56.44\%) trailed by Escherichia coli (22.42\%), Proteus mirabilis (4.38\%) and Enterobacter cloacae (2.32\%). Contrarily, the relative abundance of efflux pumps was higher in Escherichia coli (75\%), Klebsiella pneumoniae (8.33\%), and Enterobacter cloacae (8.33\%) (Fig. 5b). Within $\beta$-lactamase, different variants of extended spectrum $\beta$-lactamase (ESBL) such as SHV, TEM, OKP, and CTX-M were predominantly associated with Klebsiella pneumoniae (Additional file 1: Table S5).

\section{Reconstruction of the microbial genome and comparative genomics}

In this study, we reconstructed a microbial genome of 3.5 Mb. RAST analysis (RAST Id: 6666666.356227) depicted that reconstructed microbial genome of 3,501, 394 bp size consisted of 3464 coding sequences and 383

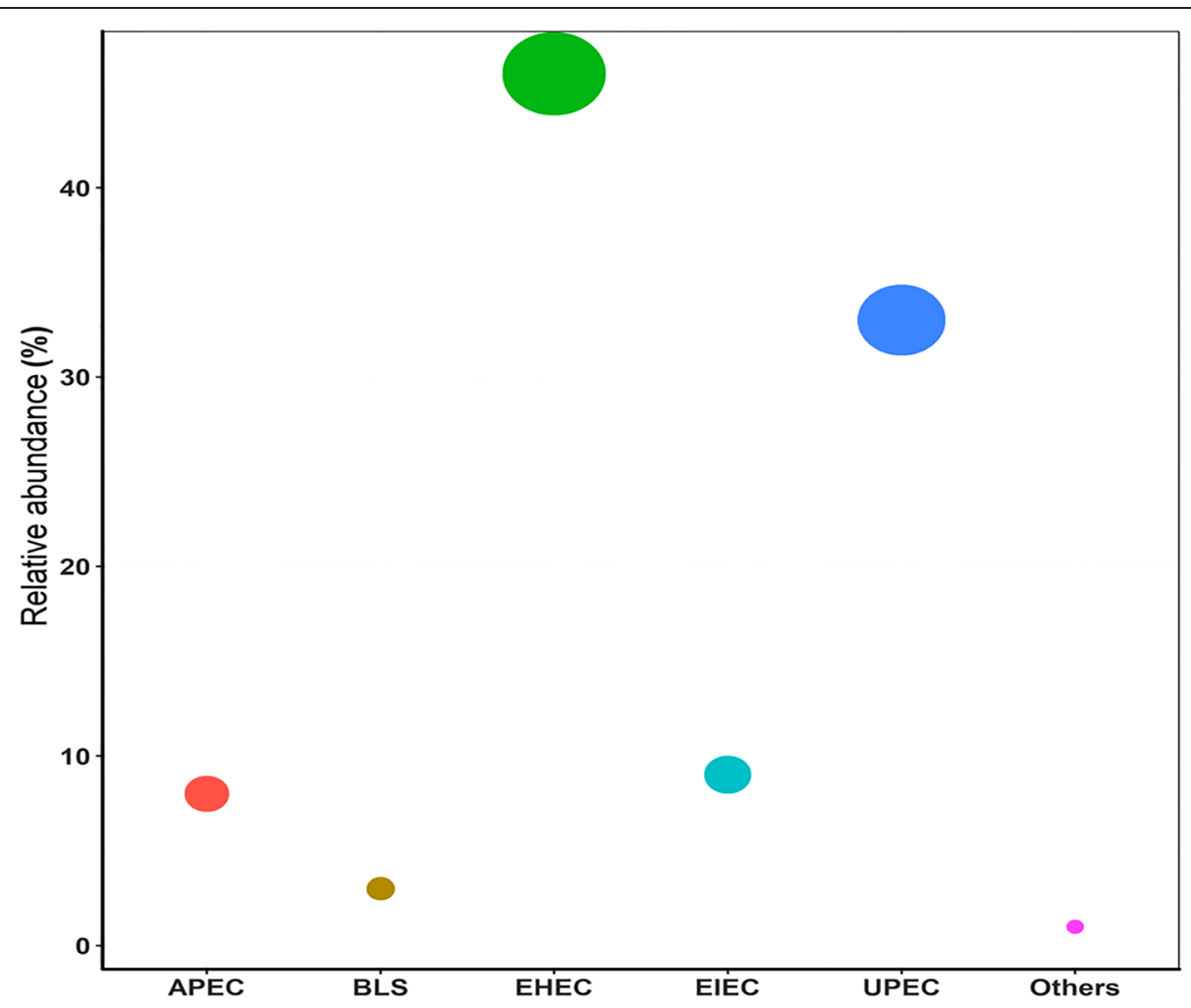

Fig. 4 Bubble plot showing distribution of different entero-virulent Escherichia coli pathotypes in the fish gut ascertained on the basis of virulence genes associated with each strain. The diameter of the circle represents the relative proportion (\%) of the particular Escherichia coli strains depending upon the relative abundance of virulence genes associated with them 


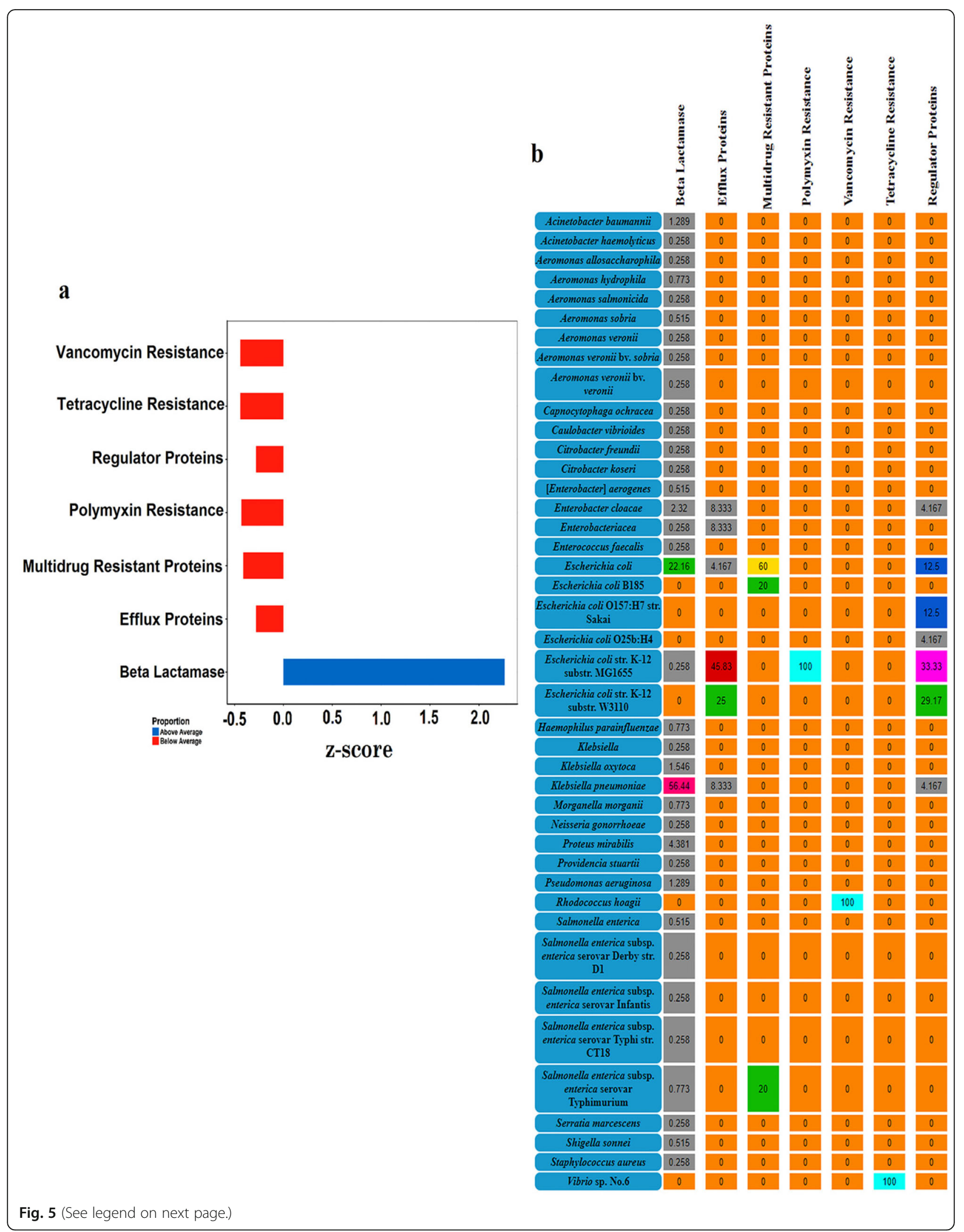


(See figure on previous page.)

Fig. 5 Antibiotic resistance pattern of gut microbiome in endangered Tor putitora. a Distribution of different antibiotic resistance genes in the fish gut microbiome. The data was normalized and the calculation of $z$-score showed the highly abundant genes for different variants of extended spectrum $\beta$-lactamases. $\mathbf{b}$ The relative distribution of antibiotic resistance genes in different bacteria present in the gut of Tor putitora. The colour code indicates the distribution of ARGs ranging from none to $100 \%$. All the zero values are given in orange. The percentages varying from 0 to $10 \%$ are highlighted grey. The 10-20\% interval is shaded blue while $20-30 \%$ range is represented by green colour. The magenta, darkred, dark-pink and yellow colour code represent $30-40 \%, 40-50 \%, 50-60 \%$ and $60-70 \%$ distribution, respectively whereas turquoise highlights 100\% abundance

subsystems and showed close resemblance with Aeromonas veronii B565, Aeromonas hydrophila subsp. hydrophilaATCC 7966, and Aeromonas salmonicida subsp. salmonicida A449. To further gain insight into the precise phylogenetic relatedness, whole genome-based average nucleotide identity (ANI) analysis was performed using publicly available representative genomes of Aeromonas species. Estimates of ANI values (>94\%) showed that reconstructed microbial genome clustered together with strains of Aeromonas veronii (Fig. 6a, Additional file 1: Table S6). Henceforth, it was designated as Aeromonas veronii strain RL.

The pathogenicity of Aeromonas species is linked to different virulence factors, including adhesion proteins, siderophore secretion, toxins, and lipopolysaccharides (LPSs). In order to confirm the pathogenic properties of strain RL, we performed its comparative genomic analyses with reported pathogenic strains of Aeromonas veronii and an uncharacterized Aeromonas sp. 159, which was phylogenetically closer to selected Aeromonas veronii strains. A close look at the number of orthologous genes revealed the presence of 1627 single-copy genes (core) determined using the GET_HOMOLOGUES pipeline (Fig. 6b). Genes encoding different virulence factors including LPS biosynthetic gene cluster, hemolysin, flagellar biosynthesis and assembly, siderophore secretion, two-component system, type I, and type II proteins, type IV pilus genes, outer membrane porin proteins, proteases were conserved in Aeromonas veronii genomes. In addition, genes encoding efflux pumps, $\beta$ lactamase, multidrug resistance proteins, dihydrofolate reductase, resistance-nodulation-cell division (RND) multidrug efflux transporters and major facilitator superfamily (MFS) were also present in the core genome. Interestingly, quorum-sensing regulator protein, which is directly involved in the pathogenesis, was found in the core (Additional file 1: Table S7). Strain RL also harboured genes encoding different virulence factors viz. lipase, collagenase, hemolysin, phospholipase $\mathrm{C}$, and serine protease. In addition, strain RL and Aeromonas veronii TH0426 harboured L-serine dehydratase, which was earlier considered unique to hypervirulent strains of Aeromonas hydrophila (Table 1, Additional file 1: Table S8).

\section{Discussion}

The values of the Shannon-Wiener index $(\mathrm{H})$ were in the range of $1.8-2.4$, and Simpson's index value (1-D) varied from $0.8-0.9$, which was consistent with values reported by other studies [52-54] indicating considerable sample diversity in the metagenomes. The composition of gut microbiota has been explored in different fish species as a function of dietary changes, the impact of host genotype, and different environmental factors [1, $2,55-58]$. The beta diversity analysis also showed variations from site 1 to site 2, mainly because microbiome composition can be influenced by the environment [58]. Studies have confirmed the influence of gut microbiota in host development, physiology, and health maintenance $[22,55,59]$. Therefore, a comprehensive analysis of the taxonomic composition and function of gut microbiota of endangered Tor putitora is crucial for understanding the influence of gut microflora on the host. To our best knowledge, the present study is the first report showing shotgun metagenomic analysis of microbial communities present in the gut of an endangered freshwater fish. In this study, Proteobacteria were dominantly present in the intestinal tract of Tor putitora, which conforms to previous studies including Prussian carp, grass carp, crucian carp, bighead carp, and Labeo rohita (rohu) $[1,2,19,57,60,61]$. Studies have also shown the presence of Chloroflexi, Actinobacteria, Firmicutes, Fusobacteria, and Bacteroidetes in the intestinal tract of different carp species [7, 57, 58, 60-64].

Fish are in continuous contact with the complex and dynamic planktonic microbiota; therefore, it is expected that the gut microbiota in fish is largely affected by microbes in the environment [65]. The dominant microbiota in the intestinal contents of carps included bacteria from families Caulobacteraceae, among others [66]. Also, the prey of different fish species in the Chany (eutrophic) lake showed relatively higher abundances of bacteria from family Caulobacteraceae [66]. The high relative abundance of genus Caulobacter in the gut of Tor putitora could be attributed to its feeding on insects, macrophytes, rotifers, and small fish [45]. The intestine of healthy juvenile salmon had Caulobacter as one of their main bacterial components [67]. The occurrence of Caulobacter spp. on the eggs of Gadus morhua L. and 


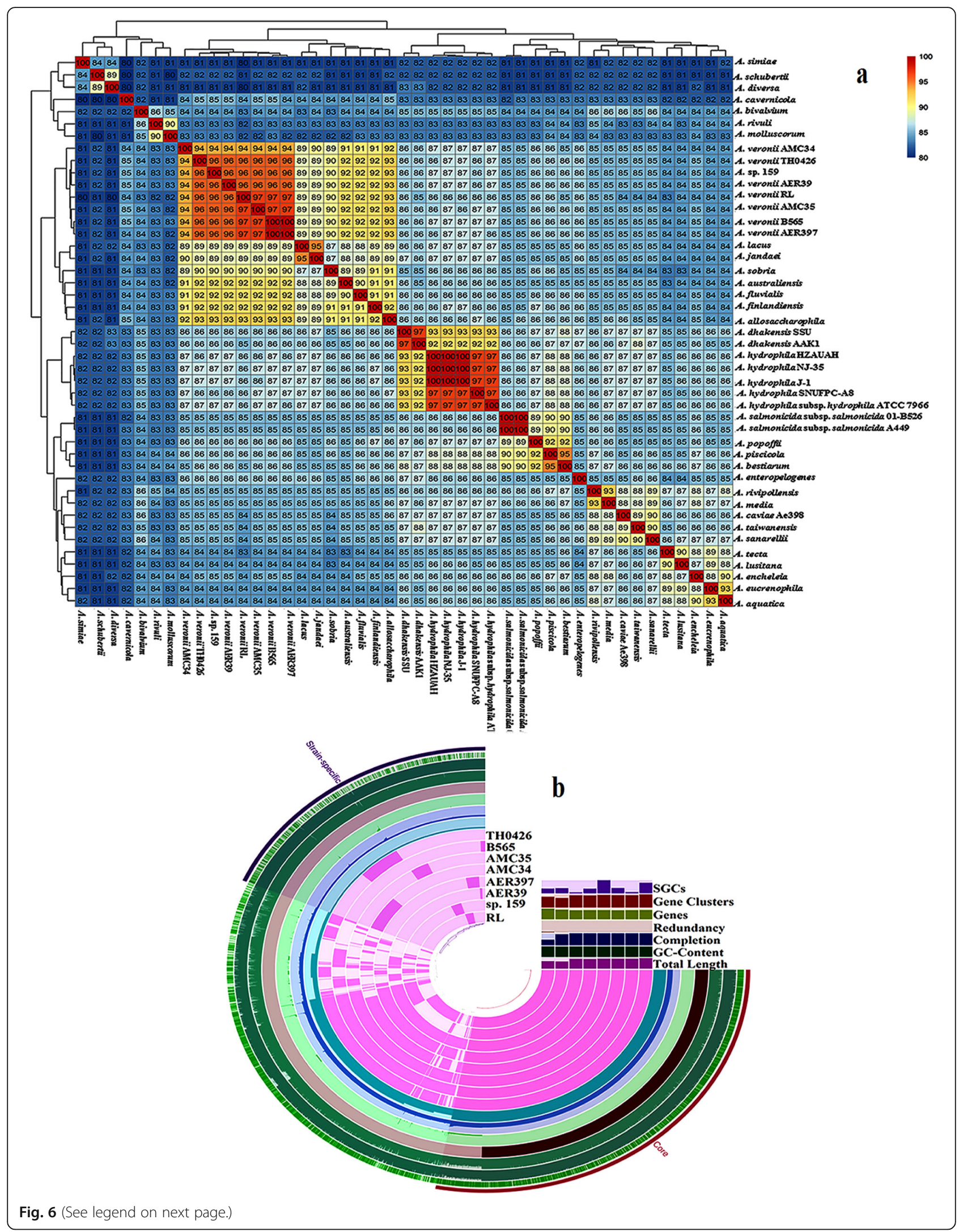


(See figure on previous page.)

Fig. 6 Comparative genome analysis of Aeromonas veronii strain RL. a Phylogenetic relatedness of Aeromonas veronii strain RL based on the average nucleotide identity values. $\mathbf{b}$ Distribution of gene clusters (core and strain-specific content) in Aeromonas veronii strain RL and its other closely related strains. The diagram is based on presence and absence of genes using Euclidean distance and Ward linkage. The strains' name are used to represent the genotypes for different strains of Aeromonas veronii, RL - Aeromonas veronii RL, sp. 159 - Aeromonas sp. 159, AER39 Aeromonas veronii AER39, AER397 - Aeromonas veronii AER397, AMC34 - Aeromonas veronii AMC34, AMC35 - Aeromonas veronii AMC35, B565 Aeromonas veronii B565, TH0426 - Aeromonas veronii TH0426

Hippoglossus hippoglossus indicated that eggs were colonized by bacteria before spawning and could be because of preinvasion from the gut [68]. Alongside resident autochthonous microbes, the fish gut is considered as the principal reservoir of Aeromonas, Pseudomonas, Vibrio, Streptococcus, Mycobacterium, and other coliforms [26-30, 41]. The presence of Escherichia coli in different tissues and organs of the fish indicates the bacteriological conditions of the water inhabited by the fish [29]. In Gobindsagar lake, which was our sampling site, industrial and domestic effluents are discharged into the water body, it is also used for bathing and recreational activities, thereby deteriorating the quality of water $[69$, 70]. Thus, pathogenic microbes from such polluted environments can be transmitted to fish, thereby colonizing their guts [26]. Moreover, the relatively high prevalence of $E$. coli in the gut could be because they multiply rapidly when the temperature is between $16^{\circ} \mathrm{C}$ and $20^{\circ} \mathrm{C}$ [29] and in the present study, the water temperature was $18.033 \pm 0.153^{\circ} \mathrm{C}$ at sampling site 1 and $20.467 \pm$ $0.451{ }^{\circ} \mathrm{C}$ at sampling site 2 (Additional file 1: Table S9). Also, they have long retention periods suggesting that they could carry bacteria in their digestive tract to nonpolluted water [29]. Klebsiella pneumoniae is an opportunistic pathogen responsible for causing nosocomial infections and are found in the gastrointestinal tract of the host [71, 72]. Again, the presence of $K$. pneumoniae in the gut may relate to the water environment, and its presence has been reported from tilapia, rohu [19, 73]. Being an opportunistic pathogen, it may cause disease under favorable conditions, as was the case in Maldive's clown fish when the concentration of unionized ammonia increased in the culture tank [74]. Pseudomonas species are another group of bacterial communities that are frequently associated with fish as one of the dominant microbes and have been isolated from their skin, gills and intestine [13, 35, 75-77]. Pseudomonas might aid in digestion by the production of proteases and along with Photobacterium spp. might produce chitinases [75]. Also, these species have been evaluated as potential probiotics in aquaculture [78-80], and their live inoculum can be used to mitigate oomycete diseases [81]. Tripathy et al. (2007) proposed that they are widespread and numerous, hence may act as secondary invaders of fish compromised with pathogens and may become involved in the disease processes [39, 76]. Thus, there is a very blurred boundary between pathogens and commensals [82].

Table 1 Presence and absence matrix of different virulence factors among known pathogenic strains of Aeromonas species

\begin{tabular}{|c|c|c|c|c|c|c|c|c|}
\hline Virulence factors & $\begin{array}{l}\text { A. veronii } \\
\mathrm{RL}\end{array}$ & $\begin{array}{l}\text { A. veronii } \\
\text { B565 }\end{array}$ & $\begin{array}{l}\text { A. veronii } \\
\text { TH0426 }\end{array}$ & $\begin{array}{l}\text { A. hydrophila } \\
\text { ATCC } 7966\end{array}$ & $\begin{array}{l}\text { A. hydrophila } \\
\text { HZAUAH }\end{array}$ & $\begin{array}{l}\text { A. hydrophila } \\
\text { J1 }\end{array}$ & $\begin{array}{l}\text { A. hydrophila } \\
\text { NJ } 35\end{array}$ & $\begin{array}{l}\text { A. salmonicida } \\
\text { A449 }\end{array}$ \\
\hline Lipase & + & + & + & + & + & + & + & + \\
\hline Serine Protease & + & + & + & + & + & + & + & + \\
\hline Collagenase & + & + & + & + & + & + & + & + \\
\hline Phospholipase C & + & + & + & + & + & + & + & + \\
\hline Metalloprotease & + & + & + & + & + & + & + & + \\
\hline $\begin{array}{l}\text { L-serine } \\
\text { dehydratase }\end{array}$ & + & - & + & + & + & + & + & - \\
\hline Oligopeptidase A & + & + & + & + & + & + & + & + \\
\hline $\begin{array}{l}\text { Sensor histidine } \\
\text { protein kinase }\end{array}$ & + & + & + & + & + & + & + & + \\
\hline Hemolysin & + & + & + & + & + & + & + & + \\
\hline $\begin{array}{l}\text { Thermostable } \\
\text { hemolysin }\end{array}$ & + & + & + & + & + & + & + & + \\
\hline $\begin{array}{l}\text { Cytolysin and } \\
\text { hemolysin (Hly A) }\end{array}$ & - & - & - & - & + & + & + & + \\
\hline
\end{tabular}


Human beings have used large amounts of antibiotics as growth factors in aquaculture, agriculture, and livestock, resulting in the contamination of the immediate environment [83]. The pathogens then exploit community changes induced by antibiotics, wherein microbiome serves as a reservoir of virulence factors and resistance determinants [82]. Given that many virulence genes are coded in extra-chromosomal elements, the horizontal transfer of such genes to other non-pathogenic species might occur by genetic elements of varying mobility such as plasmids and transposable elements [84, 85]. The functional annotation of gut metagenome revealed the presence of different mobile genetic elements that might aid in the transfer of virulence properties to harmless strains rendering them potential pathogens [83]. Also, it has been stated that virulence factors are needed in bacteria's "struggle for existence" against microscopic adversaries [82]. For example, enterohemorrhagic serotype Escherichia coli O157:H7 (EHEC) is a commensal in the bovine gut, but acts as a pathogen for humans [82]. Therefore, it could be concluded that the presence of virulence factors in the fish gut metagenome may not be an indication of unhealthy gut microbiota but can serve as a reservoir for dissemination of genes to mutualistic or commensal bacteria which can pose a serious threat to fish and public health by their virtue of being converted into potential pathogens. Escudeiro et al. (2019) proposed that there exists a correlation between antibiotic resistance determinants and virulence factors diversity in metagenomes and speculated that by selecting for resistant bacteria, we may end up selecting for more virulent strains as a side effect of antibiotics usage [83]. Antibiotic resistance genes have been frequently reported in isolates belonging to the families Pseudomonadaceae, Enterobacteriaceae, and Rhizobiaceae [84]. Besides, multidrug-resistant strains of Escherichia coli and Klebsiella pneumoniae have been reported from wild and commercial fish and other seafood [43, 86-88]. The extended-spectrum $\beta$-lactamase (ESBL) was found to be predominantly associated with Klebsiella pneumoniae present in the gut of Tor putitora. Similar to this study, genes encoding extended spectrum betalactamase (TEM, CTX-M-1) and multidrug resistance proteins ( $m d t A, m d t B, m d t C$ ) were also found in the gut microbiome of freshwater Indian carp [19].

Members of Aeromonas have been reported from fish with a wide range of both beneficial and pathogenic outcomes [75, 89, 90]. The furunculosis committee had considered the fish intestine as an important niche for the isolation of Aeromonad species [35, 91-93]. In this study, the prominently detected Aeromonas species were Aeromonas hydrophila, Aeromonas salmonicida, and Aeromonas veronii. Several virulence factors have been characterized for Aeromonas species, and the type III secretion system (TTSS), which can efficiently inject anti-host virulence determinants (toxins) into the host cells, is main virulent factor reported in strains of Aeromonas salmonicida and Aeromonas hydrophila [51, 9497]. Functional investigation showed the presence of different virulence genes of Aeromonas hydrophila, and complete operon encoding TTSS of Aeromonas salmonicida (Fig. 3b, Additional file 1: Table S2). The role of genes encoding flagellar apparatus, and bacterial chemotaxis has been well elucidated in Helicobacter pylori, Pseudomonas aeruginosa, Vibrio cholerae allowing them to colonize and invade the host's mucosa [98]. Apart from these, type IV pili serve as important structures for adhesion to epithelial cells and are involved in biofilm formation and twitching motility [98]. These observations suggest the presence of virulent strains of Aeromonas in the gut of Tor putitora, indicating that intestine may be a possible route of infection. Moreover, the reconstruction of Aeromonas veronii strain RL genome reflected its abundance. Aeromonas veronii strains have been conspicuously detected in the intestine of fish [30, 99]. Recently, Aeromonas jandaei and Aeromonas veronii were reported as the disease causative agent and linked to mortality in Nile tilapia [91]. Core genome analysis highlighted the virulent properties of strain RL and showed the conservation of virulence genes. Comparative genome analysis confirmed the virulent properties of strain RL genome, which harbored several virulence genes encoding lipase, collagenase, hemolysin, thermostable hemolysin, phospholipase $\mathrm{C}$ and serine protease which are well-characterized virulence factors of Aeromonas species [94]. Intriguingly, strain RL possessed a gene encoding L-serine dehydratase, which was earlier considered to be uniquely present in hypervirulent strains of Aeromonas hydrophila. The role of L-serine dehydratase in the colonization of the avian gut by Campylobacter jejuni has been reported [100]. The presence of virulent properties does not reflect that they are actual pathogens; however, under conditions of stressinduced infections, the gut may be the primary location for colonization by Aeromonas. Clearly, additional studies are needed to understand the role of Aeromonas species in the gut of Tor putitora.

Previous studies had shown that intestinal microbiota of freshwater fish is dominated by phyla such as Proteobacteria, Fusobacteria, Firmicutes, and Bacteroidetes whose members are able to decompose plant polymers and ferment organic compounds providing nutrients and energy to fish [7, 35, 58, 60, 62, 101, 102]. Aeromonas species, representative of Gammaproteobacteria, are well-characterized fish pathogens, but beneficial cellulose-degrading Aeromonas species had also been cultured from the intestinal tract of grass carp [2]. Likewise, Cetobacterium (Fusobacteria), which can produce 
vitamin $B_{12}$ were abundantly present in the intestinal tract of Cyprinus caprio and Tor tambroides [7, 103, 104]. Interestingly, occurrences of symbiotic bacteria such as Bradyrhizobium and Mesorhizobium, which are generally associated with plant roots, reflect the omnivorous feeding habit of Tor putitora [45]. The diverse microbial community present in the gut of Tor putitora comprised of both non-pathogenic (symbiotic or beneficial) microbes and putative pathogens. The diverse intestinal communities are more beneficial for their host and stable to environmental disturbances [65]. Consistent with this statement, higher alpha diversity was frequently detected in the healthy fish compared to diseased fish [65], and measures of alpha diversity in Tor putitora were comparable to those in healthy fish in other studies [65]. The environmental factors adversely affecting the non-pathogenic community (microbial dysbiosis) would possibly decrease the competition to gut pathogens allowing their colonization and proliferation in the gut of Tor putitora. Also, the risk involved in the consumption of contaminated fish may not necessarily be associated with bacteria present in the edible tissues, but infection may also occur during handling of the fish, cross-contamination to other food sources is likely to occur when the fish is prepared and cleaned for consumption. Also, the presence of antibiotic-resistant strains in the gut poses a threat to public health by their virtue of being consumers.

\section{Conclusions}

The present study is a pioneer attempt to investigate the microbial diversity and functional potential of gut microbial communities of endangered fish Tor putitora. This fish species is vital for ecological and ecosystem stability; thus, potential mobilization of antibiotic resistance genes through gut microbes has serious implications both for the fish and human health. This baseline data on gut microbiome clears that the microbiota affects its host in more than one way, and this study is thought to bring a plenitude of understanding of their functional potential in the host and expand current notions of the fish gut microbiome.

\section{Methods}

\section{Site selection and sampling}

In this study, sampling was performed from two fish landing stations located at the Gobindsagar reservoir, Himachal Pradesh, India (Fig. 7). The first sampling was done from Gulehar site $\left(31.4047^{\circ} \mathrm{N}, 76.4968^{\circ} \mathrm{E}\right.$; lotic water system) and second sampling site was Bhakra barrage $\left(31.5269^{\circ} \mathrm{N}, 76.3968^{\circ} \mathrm{E}\right.$; lentic water system). A total of ten healthy fish specimens ranging from 50-53 $\mathrm{cm}$ in length and 1650-2250 g in weight were collected from each of the two sites (Additional file 1: Table S10).
Samples were brought to the laboratory in dry ice. Each fish was aseptically dissected for its whole gut contents, and samples were stored at $-80^{\circ} \mathrm{C}$. The Physicochemical parameters of water such as temperature, $\mathrm{pH}$, electrical conductivity, total dissolved solids (TDS) and dissolved oxygen (DO) were measured immediately after sampling by an Orion 5-Star Portable $\mathrm{pH} / \mathrm{ORP} / \mathrm{DO} /$ Conductivity Multimeter (Thermo Fisher Scientific Inc. [NYSE: TMO], MA, USA).

\section{DNA isolation, sequencing and data processing}

The DNA was isolated from the whole gut contents of each fish sample using a metagenomic DNA isolation kit (PowerSoil ${ }^{\circ}$ DNA Isolation Kit, MO BIO). The metagenomic DNA was quantified using the NanoDrop ND1000 spectrophotometer (NanoDrop Technologies, Inc., Wilmington, DE, USA). The metagenomic DNA was visualized on $0.8 \%$ agarose gel electrophoresis. The DNA from each fish gut content sample was pooled in equimolar concentration for fish gut metagenome 1 (FGM1) and fish gut metagenome 2 (FGM2) samples representing sampling site 1 and sampling site 2 , respectively [58, 63]. The whole metagenome shotgun DNA sequencing was performed at Beijing Genomics Institute (Shenzhen, China) on Illumina HiSeq 2500 platform. The raw data were processed for a quality check using the FastQC software [105]. The duplicate's reads were removed using Picard [106], and any reads with a quality score of less than 20 were discarded.

\section{Taxonomic and functional characterization}

Microbial diversity was analyzed on filtered reads using MetaPhlAn, which has its own database comprising of $\sim 1 \mathrm{M}$ unique clade-specific marker genes [21, 107]. For the classification at the species level, the relative abundances were normalized according to the median genome size of each predicted species and the number of total reads in the sample [108, 109]. The rarefaction analysis and alpha and beta diversity measures were computed in Megan6 [110]. For functional characterization, raw reads were submitted for BLAST search against the $n r$ database using diamond BLASTx at e-value 1e-3, similarity $\geq 90 \%$, and alignment length $>20$ amino acids [111]. Using the best-hit algorithm, individual reads were described to belong to a class in the particular classification system [112]. The method was as follows: For a read ' $r$ ', let ' $a$ ' describe the highest-scoring alignment to a reference protein belonging to functional class ' $c$ ' and the number of reads that mapped to the individual proteins were then analysed using databases eggNOG [113], KEGG [114] and SEED [115]. The data was normalized by dividing the binned read counts for each pathway with the number of total reads in the sample [109]. 


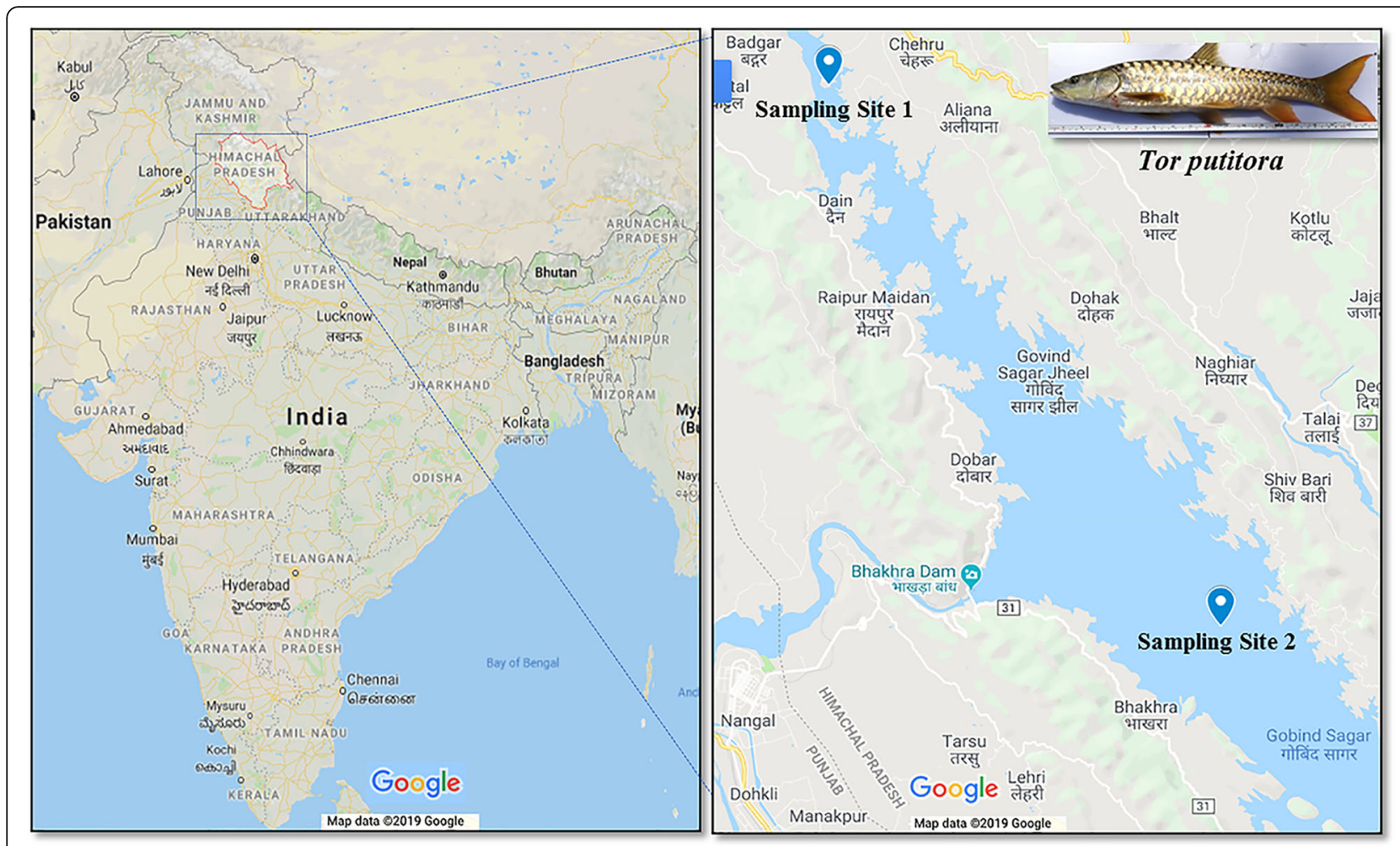

Fig. 7 The map of sampling location indicating the two points of collection of fish samples from Gobindsagar reservoir, Himachal Pradesh, India

\section{Detection of virulence and antibiotic resistance genes}

The de novo assembly of paired-end reads from each sample was done using IDBA-UD at different k-mers [116]. The open reading frames (ORFs) were then predicted on the assembled contigs using FragGeneScan [117]. The protein sequences encoded by virulence genes of Aeromonas and Pseudomonas were retrieved from Virulence Factors Database (VFDB) [118]. Likewise, Escherichia coli virulence factors (EVF) database was created using the protein sequences encoded by different virulence genes of Escherichia coli available at VFDB [118], and Victors Virulence Factors database [119]. Distribution of antibiotic resistance genes in fish gut metagenome was analyzed using 'The Comprehensive Antibiotic Resistance Database' (CARD) [42, 120, 121]. The z-score for antibiotic resistome was calculated using the mean and standard deviation of the abundances of all individual antibiotic resistance genes in the fish gut metagenome. The BLASTp searches were performed using the assembled contigs to identify the virulence genes (Escherichia coli, Aeromonas spp. and Pseudomonas spp.) and major ARGs. The virulence genes and ARGs which fulfilled the following similarity criteria (cut off): e-value $<1 \mathrm{e}-5$, percent identity $\geq$ $80 \%$, alignment length/subject length $\geq 0.8$, and alignment length/query length $\geq 0.8$ were included in the study [122].

\section{Assembly of the microbial genome and comparative genomics}

The microbial genome was reconstructed from the gut metagenome sequence using Metabat2 [123, 124]. The quality and completeness of the assembled genome was checked using CheckM [125]. The reconstructed genome was annotated using Rapid Annotations using Subsystems Technology (RAST) [126]. For comparative genome analysis, all the nearest neighbours annotated in RAST, as well as the representative genotypes available at National Center for Biotechnology Information (NCBI), were included [127]. Whole genome-based ANI analysis was done, and genomes were clustered using kmeans clustering. The clustering analysis revealed the monophyletic neighbours of the metagenome assembled genome (MAG) and orthologous gene identification was performed using the GET_HOMOLOGUES pipeline [128] at the following criteria: -E value 1e-5 (expectation value), $-\mathrm{C} \geq 75$ (percentage coverage in BLAST alignments) and -F 1.5 (inflation value).

\section{Supplementary information}

Supplementary information accompanies this paper at https://doi.org/10. 1186/s12866-020-01911-7.

Additional file 1 Supplementary tables. Supplementary Table S1. contains details regarding sequencing and assembly of the 
metagenomes FGM1 and FGM2. Table S2, Table S3 and Table S4. contain list of virulence factors of Aeromonas species, Escherichia coli pathotypes and Pseudomonas species identified in gut metagenome. Table S5. enlists the antibiotic resistome of fish gut metagenome. Table S6. describes the general genome features of Aeromonas veronii strain RL and its nearest neighbours, while Table S7. lists core genes conserved in the selected genomes of Aeromonas veronii strains. Table S8. is the RAST annotations of assembled genome of Aeromonas veronii strain RL. Table S9. provides an account of various physico-chemical properties of water collected from two sampling sites mentioned in Table $\mathbf{S 1 0}$ and depicted in Fig. 7. Table S10. describes length and weight of the fish species collected from Gobindsagar reservoir (Gulehar and Bhakra).

Additional file $\mathbf{2}$ Supplementary figures. Figure $\mathbf{S 1}$. shows the rarefaction curves of samples. Figure $\mathbf{S 2}$. depicts the beta diversity estimates of the samples using Non-metric Multi-Dimensional Scaling plot based on Whittaker distance. Figure $\mathbf{S 3}$. shows the relative abundance of different virulence factors of Pseudomonas spp.

\section{Abbreviations}

ARGs: Antibiotic Resistance Genes; FGM: Fish Gut Metagenome; TTSS: Type III Secretion System; EHEC: Enterohemorrhagic Escherichia coli

\section{Acknowledgements}

The authors are grateful to the Himachal Pradesh State Biodiversity Board, Himachal Pradesh, India for allowing us to conduct this research. We would also like to thank the members of the Department of Fisheries Himachal Pradesh for helping us in the field sampling.

\section{Authors' contributions}

RKN, RL and YS conceived the idea of study and sampling design. Samples were collected by RKN and HK. HK and DNS performed the analysis and wrote the manuscript. HK, DNS and AS compiled figures of manuscript. All authors read and approved the final manuscript.

\section{Funding}

This study was supported by grants received from the Indian Council of Agricultural Research funded National Bureau of Agriculturally Important Microorganisms (NBAIM, grant number NBAIM/AMAAS/2017-20/GF/1a) for purchase of DNA isolation kits and cover the cost of travel, field sampling and sequencing of the samples. This research was also supported by fellowships received from Indian Council of Medical Research (ICMR), University Grants Commission (UGC) and Council of Scientific and Industrial Research (CSIR).

\section{Availability of data and materials}

The raw sequencing read data set and metagenome assembled microbial genome have been deposited in the European Nucleotide Archive (ENA) under the project accession number PRJEB30661, https://www.ebi.ac.uk/ena/ data/search?query=PRJEB30661.

\section{Ethics approval and consent to participate}

Fish sampling was performed as per ethical approval from Himachal Pradesh State Biodiversity Board, Himachal Pradesh, India (SCSTE/HPSBB/2016/- 6722 dated 06-12-2016)

\section{Consent for publication}

Not applicable.

\section{Competing interests}

The authors declare that they have no competing interests.

\section{Author details}

'Fish Molecular Biology Laboratory, Department of Zoology, University of Delhi, Delhi 110007, India. ${ }^{2}$ Molecular Biology Laboratory, Department of Zoology, University of Delhi, Delhi 110007, India. 'aboratory of Microbial Pathogenesis, Department of Zoology, University of Delhi, Delhi 110007, India. ${ }^{4}$ Present address: The Energy and Resources Institute Darbari Seth Block, IHC Complex, Lodhi Road, New Delhi 110003, India.
Received: 21 August 2019 Accepted: 19 July 2020

Published online: 12 August 2020

\section{References}

1. Li T, Long M, Gatesoupe FJ, Zhang Q, Li A, Gong X. Comparative analysis of the intestinal bacterial communities in different species of carp by pyrosequencing. Microb Ecol. 2015;69:25-36

2. Wu S, Wang G, Angert ER, Wang W, Li W, Zou H. Composition, diversity, and origin of the bacterial community in grass carp intestine. PLoS One. 2012;7: e30440.

3. Walter J, Britton RA, Roos S. Host-microbial symbiosis in the vertebrate gastrointestinal tract and the Lactobacillus reuteri paradigm. Proc Natl Acad Sci U S A. 2011:108:4645-52.

4. Qi XZ, Tu X, Zha JW, Huang AG, Wang GX, Ling F. Immunosuppressioninduced alterations in fish gut microbiota may increase the susceptibility to pathogens. Fish Shellfish Immunol. 2019;88:540-5.

5. She R, Li TT, Luo D, Li JB, Yin LY, Li H, et al. Changes in the intestinal microbiota of gibel carp (Carassius gibelio) associated with cyprinid herpesvirus 2 (CyHV-2) infection. Curr Microbiol. 2017;74:1130-6.

6. Xing M, Hou Z, Yuan J, Liu Y, Qu Y, Liu B. Taxonomic and functional metagenomic profiling of gastrointestinal tract microbiome of the farmed adult turbot (Scophthalmus maximus). FEMS Microbiol Ecol. 2013:86:432-43.

7. van Kessel MA, Dutilh BE, Neveling K, Kwint MP, Veltman JA, Flik G, et al. Pyrosequencing of 165 rRNA gene amplicons to study the microbiota in the gastrointestinal tract of carp (Cyprinus carpio L.). AMB Express. 2011;1:41.

8. Ley RE, Lozupone CA, Hamady M, Knight R, Gordon JI. Worlds within worlds: evolution of the vertebrate gut microbiota. Nat Rev Microbiol. 2008; 6:776-88.

9. Flint HJ, Bayer EA, Rincon MT, Lamed R, White BA. Polysaccharide utilization by gut bacteria: potential for new insights from genomic analysis. Nat Rev Microbiol. 2008;6:121-31.

10. Sugita $H$, Miyajima $C$, Deguchi $Y$. The vitamin $B_{12}$-producing ability of the intestinal microflora of freshwater fish. Aquaculture. 1991:92:267-76.

11. Li T, Li H, Gatesoupe FJ, She R, Lin Q, Yan X, et al. Bacterial signatures of "Red-Operculum" disease in the gut of crucian carp (Carassius auratus). Microb Ecol. 2017;74:510-21.

12. Ring $\varnothing$ E, Myklebust R, Mayhew TM, Olsen RE. Bacterial translocation and pathogenesis in the digestive tract of larvae and fry. Aquaculture. 2007;268: 251-64

13. Parshukov AN, Kashinskaya EN, Simonov EP, Hlunov OV, Izvekova Gl, Andree $\mathrm{KB}$, et al. Variations of the intestinal gut microbiota of farmed rainbow trout, Oncorhynchus mykiss (Walbaum), depending on the infection status of the fish. J Appl Microbiol. 2019;127:379-95.

14. Kho ZY, Lal SK. The human gut microbiome - a potential controller of wellness and disease. Front Microbiol. 2018;9:1835.

15. Colston TJ, Jackson CR. Microbiome evolution along divergent branches of the vertebrate tree of life: what is known and unknown. Mol Ecol. 2016;25: 3776-800.

16. Ghanbari M, Kneifel W, Domig KJ. A new view of the fish gut microbiome: advances from next-generation sequencing. Aquaculture. 2015:448:464-75.

17. He S, Zhou Z, Banerjee G, Huang L, Ray AK, Ringø E. Bacterial diversity in the digestive tracts of four Indian air-breathing fish species investigated by PCR based denaturing gradient gel electrophoresis. Braz Arch of Biol Technol. 2016;59:e16160332.

18. Zapka C, Leff J, Henley J, Tittl J, De Nardo E, Butler M, et al. Comparison of standard culture-based method to culture-independent method for evaluation of hygiene effects on the hand microbiome. mBio. 2017;8: e00093-17.

19. Tyagi A, Singh B, Billekallu Thammegowda NK, Singh NK. Shotgun metagenomics offers novel insights into taxonomic compositions, metabolic pathways and antibiotic resistance genes in fish gut microbiome. Arch Microbiol. 2019;201:295-303.

20. Tarnecki AM, Burgos FA, Ray CL, Arias CR. Fish intestinal microbiome: diversity and symbiosis unravelled by metagenomics. J Appl Microbiol. 2017:123:2-17.

21. Jovel J, Patterson J, Wang W, Hotte N, O'Keefe S, Mitchel T, et al. Characterization of the gut microbiome using $16 \mathrm{~S}$ or shotgun metagenomics. Front Microbiol. 2016;7:459.

22. de Bruijn I, Liu Y, Wiegertjes GF, Raaijmakers JM. Exploring fish microbial communities to mitigate emerging diseases in aquaculture. FEMS Microbiol Ecol. 2018;94:fix161. 
23. Di Maiuta N, Schwarzentruber P, Schenker M, Schoelkopf J. Microbial population dynamics in the faeces of wood-eating loricariid catfishes. Lett Appl Microbiol. 2013;56:401-7.

24. Semova I, Carten JD, Stombaugh J, Mackey LC, Knight R, Farber SA, et al. Microbiota regulate intestinal absorption and metabolism of fatty acids in the zebrafish. Cell Host Microbe. 2012;12:277-88.

25. Qiu Y, Cai CF, Dai XF, Ye YT, Yin XJ. Effects of Bacillus subtilis on growth performance and microvilli of grass carp. China Food. 2010;19:34-6.

26. Foysal MJ, Momtaz F, Robiul Kawser AQM, Chaklader MR, Siddik MAB, Lamichhane $B$, et al. Microbiome patterns reveal the transmission of pathogenic bacteria in Hilsa fish (Tenualosa ilisha) marketed for human consumption in Bangladesh. J Appl Microbiol. 2019;126:1879-90.

27. Hossain ZZ, Farhana I, Tulsiani SM, Begum A, Jensen PKM. Transmission and toxigenic potential of Vibrio cholerae in hilsha fish (Tenualosa ilisha) for human consumption in Bangladesh. Front Microbiol. 2018:9:222.

28. Hansen DL, Clark JJ, Ishii S, Sadowsky MJ, Hicks RE. Sources and sinks of Escherichia coli in benthic and pelagic fish. J Great Lakes Res. 2008;34:228-34.

29. Guzmán MC, Bistoni Mde L, Tamagnini LM, González RD. Recovery of Escherichia coli in fresh water fish, Jenynsia multidentata and Bryconamericus iheringi. Water Res. 2004;38(9):2367-73.

30. Sugita H, Tanaka K, Yoshinami M, Deguchi Y. Distribution of Aeromonas species in the intestinal tracts of river fish. Appl Environ Microbiol. 1995;61: 4128-30.

31. Scoaris Dde O, Colacite J, Nakamura CV, Ueda-Nakamura T, de Abreu Filho BA, Dias Filho BP. Virulence and antibiotic susceptibility of Aeromonas spp. isolated from drinking water. Antonie Van Leeuwenhoek. 2008;93:111-22.

32. Henriques IS, Fonseca F, Alves A, Saavedra MJ, Correia A. Occurrence and diversity of integrons and beta-lactamase genes among ampicillin-resistant isolates from estuarine waters. Res Microbiol. 2006;157:938-47.

33. Lehane L, Rawlin GT. Topically acquired bacterial zoonoses from fish: a review. Med J Aust. 2000;173:256-9.

34. Filler $\mathrm{G}$, Ehrich $J H H$, Strauch $\mathrm{E}$, Beutin L. Acute renal failure in an infant associated with cytotoxic Aeromonas sobria isolated from patient's stool and from aquarium water as suspected source of infection. J Clin Microbiol. 2000;38:469-70.

35. Wang $A R$, Ran C, Ringø $E$, Zhou ZG. Progress in fish gastrointestinal microbiota research. Rev Aquac. 2018;10:626-40.

36. Wu S, Gao T, Zheng Y, Wang W, Cheng Y, Wang G. Microbial diversity of intestinal contents and mucus in yellow catfish (Pelteobagrus fulvidraco). Aquaculture. 2010;303:1-7.

37. Sreedharan K, Philip R, Singh IS. Isolation and characterization of virulent Aeromonas veronii from ascitic fluid of oscar Astronotus ocellatus showing signs of infectious dropsy. Dis Aquat Org. 2011;94:29-39.

38. Alikunhi NM, Batang ZB, AlJahdali HA, Aziz MAM, Al-Suwailem AM. Culturedependent bacteria in commercial fishes: qualitative assessment and molecular identification using $16 \mathrm{~S}$ rRNA gene sequencing. Saudi J Biol Sci. 2017;24:1105-16.

39. Shahi N, Mallik SK. Recovery of Pseudomonas koreensis from eye lesions in golden mahseer, Tor putitora (Hamilton, 1822) in Uttarakhand. India J Fish Dis. 2014;37:497-500.

40. Senderovich Y, Izhaki I, Halpern M. Fish as reservoirs and vectors of Vibrio cholerae. PLoS One. 2010;5:e8607.

41. Novotny L, Dvorska L, Lorencova A, Beran V, Pavlik I. Fish: a potential source of bacterial pathogens for human beings. A review. Veterinarni MedicinaUZPI (Czech Republic). 2004;49:343-58.

42. Fu J, Yang D, Jin M, Liu W, Zhao X, Li C, et al. Aquatic animals promote antibiotic resistance gene dissemination in water via conjugation: role of different regions within the zebra fish intestinal tract, and impact on fish intestinal microbiota. Mol Ecol. 2017:26:5318-33.

43. Ryu SH, Park SG, Choi SM, Hwang YO, Ham HJ, Kim SU, et al. Antimicrobial resistance and resistance genes in Escherichia coli strains isolated from commercial fish and seafood. Int J Food Microbiol. 2012;152:14-8.

44. Guglielmetti E, Korhonen JM, Heikkinen J, Morelli L, von Wright A. Transfer of plasmid-mediated resistance to tetracycline in pathogenic bacteria from fish and aquaculture environments. FEMS Microbiol Lett. 2009;293:28-34.

45. Bhatt JP, Pandit MK. Endangered Golden mahseer Tor putitora Hamilton: a review of natural history. Rev Fish Biol Fish. 2016;26:25-38.

46. Everard M, Kataria G. Recreational angling markets to advance the conservation of a reach of the Western Ramganga River, India. Aquatic Conserv: Mar Fresh Ecosyst. 2011;21:101-8.
47. Jha BR, Rayamajhi A, Dahanukar N, Harrison A, Pinder A. Tor putitora. The IUCN red list of threatened species, vol. 2018; 2018. p. e.

T126319882A126322226. Accessed 06 Sept 2018.

48. Sarma D, Das P, Das P, Sanwa S, Akhtar MS. Nutritional composition of Golden Mahseer (Tor putitora) in Coldwater Himalayan region of India. SKUAST J Res. 2015;17:23-8.

49. Pinder AC, Britton JR, Harrison AJ, Nautiyal P, Bower SD, Cooke SJ, et al. Mahseer (Tor spp.) fishes of the world: status, challenges and opportunities for conservation. Rev Fish Biol Fish. 2019;29:417-52.

50. Department of Fisheries Himachal Pradesh. Accessed 03 Apr 2020.

51. Frey J, Origgi FC. Type III secretion system of Aeromonas salmonicida undermining the host's immune response. Front Mar Sci. 2016;3:130.

52. Ali MM, Ali ML, Rahman MJ, Wahab MA. Fish diversity in the Andharmanik River sanctuary in Bangladesh. Croat J Fisheries. 2020;78:21-32.

53. Villasante A, Ramírez C, Rodríguez H, Catalán N, Díaz O, Rojas R, et al. Indepth analysis of swim bladder-associated microbiota in rainbow trout (Oncorhynchus mykiss). Sci Rep. 2019:9:8974.

54. Türkmen GE, Kazanci Ni. Applications of various biodiversity indices to benthic macroinvertebrate assemblages in streams of a national park in Turkey. Rev Hydrobiol. 2010;3:111-25.

55. Tran NT, Zhang J, Xiong F, Wang GT, Li WX, Wu SG. Altered gut microbiota associated with intestinal disease in grass carp (Ctenopharyngodon idellus). World J Microbiol Biotechnol. 2018:34:71.

56. Carda-Diéguez M, Mira A, Fouz B. Pyrosequencing survey of intestinal microbiota diversity in cultured sea bass (Dicentrarchus labrax) fed functional diets. FEMS Microbiol Ecol. 2014:87:451-9.

57. Han S, Liu Y, Zhou Z, He S, Cao Y, Shi P, et al. Analysis of bacterial diversity in the intestine of grass carp (Ctenopharyngodon idellus) based on 16S rDNA gene sequences. Aquac Res. 2010;42:47-56.

58. Eichmiller JJ, Hamilton MJ, Staley C, Sadowsky MJ, Sorensen PW. Environment shapes the fecal microbiome of invasive carp species. Microbiome. 2016:4:44

59. Butt RL, Volkoff H. Gut Microbiota and Energy Homeostasis in Fish. Front Endocrinol (Lausanne). 2019;10:9.

60. Kashinskaya EN, Belkova NL, Izvekova Gl, Simonov EP, Andree KB, Glupov W, et al. A comparative study on microbiota from the intestine of Prussian carp (Carassius gibelio) and their aquatic environmental compartments, using different molecular methods. J Appl Microbiol. 2015;119:948-61.

61. Llewellyn MS, Boutin S, Hoseinifar SH, Derome N. Teleost microbiomes: the state of the art in their characterization, manipulation and importance in aquaculture and fisheries. Front Microbiol. 2014;5:207.

62. Xia JH, Lin G, Fu GH, Wan ZY, Lee $M$, Wang L, et al. The intestinal microbiome of fish under starvation. BMC Genomics. 2014;15:266.

63. Wu SG, Tian JY, Gatesoupe FJ, Li WX, Zou H, Yang BJ, et al. Intestinal microbiota of gibel carp (Carassius auratus gibelio) and its origin as revealed by 454 pyrosequencing. World J Microbiol Biotechnol. 2013;29:1585-95.

64. He L, Hao B, Xie C, Luo X, Zhang Z, Zhu X. Isolation and identification of major cellulase-producing fungi in intestines of grass carp. Chin J Appl Environ Biol. 2009:15:414-8.

65. Xiong JB, Nie L, Chen J. Current understanding on the roles of gut microbiota in fish disease and immunity. Zool Res. 2019;40:70-6.

66. Kashinskaya EN, Simonov EP, Kabilov MR, Izvekova Gl, Andree KB, Solovyev MM. Diet and other environmental factors shape the bacterial communities of fish gut in an eutrophic lake. J Appl Microbiol. 2018;125:1626-41.

67. Navarrete P, Mardones P, Opazo R, Espejo R, Romero J. Oxytetracycline treatment reduces bacterial diversity of intestinal microbiota of Atlantic salmon. J Aquat Anim Health. 2008;20:177-83.

68. Hansen GH, Olafsen JA. Bacterial colonization of cod (Gadus morhua L.) and halibut (Hippoglossus hippoglossus) eggs in marine aquaculture. Appl Environ Microbiol. 1989:55:1435-46.

69. Sharma V, Walia YK. Water quality assessment of Gobind Sagar Lake during rainy season in Himachal Pradesh, India. In: Biological Forum, vol. 8; 2016. p. 559-64.

70. Sharma V, Walia YK. Water quality assessment using physico-chemical parameters and heavy metals of Gobind Sagar lake, Himachal Pradesh (India). Curr World Environ. 2015;10:967-74.

71. Adeshina I, Abdrahman SA, Yusuf AA. Occurrence of Klebsiella species in cultured African catfish in Oyo state, South-West Nigeria. Nig Vet J. 2016;37:24-31.

72. Barati A, Ghaderpour A, Chew LL, Bong CW, Thong KL, Chong VC, et al. Isolation and characterization of aquatic-borne Klebsiella pneumoniae from tropical estuaries in Malaysia. Int J Environ Res Public Health. 2016;13:426. 
73. Ogbonna DN, Sokari TG, Amaku GE. Antibiogram of bacterial flora of Tilapia zilli from creeks around Port Harcourt, Nigeria. J Environ Sci Technol. 2008;1:27-33.

74. Gopi M, Kumar T, Prakash S. Opportunistic pathogen Klebsiella pneumoniae isolated from Maldive's clown fish Amphiprion nigripes with hemorrhages at Agatti Island, Lakshadweep archipelago. Int J Fisheries Aquatic Stud. 2016;4:464-7.

75. Egerton S, Culloty S, Whooley J, Stanton C, Ross RP. The gut microbiota of marine fish. Front Microbiol. 2018;9:873.

76. Tripathy S, Kumar N, Mohanty S, Samanta M, Mandal RN, Maiti NK. Characterisation of Pseudomonas aeruginosa isolated from freshwater culture systems. Microbiol Res. 2007;162:391-6.

77. Cahill MM. Bacterial flora of fishes: a review. Microb Ecol. 1990:19:21-41.

78. Nikouli E, Meziti A, Antonopoulou E, Mente E, Kormas KA. Gut bacterial communities in geographically distant populations of farmed sea bream (Sparus aurata) and sea bass (Dicentrarchus labrax). Microorganisms. 2018;6:92

79. Korkea-Aho TL, Heikkinen J, Thompson KD, Von Wright A, Austin B. Pseudomonas sp. M174 inhibits the fish pathogen Flavobacterium psychrophilum. J Appl Microbiol. 2011;111:266-77.

80. El-Rhman AM, Khattab YA, Shalaby AM. Micrococcus luteus and Pseudomonas species as probiotics for promoting the growth performance and health of Nile tilapia, Oreochromis niloticus. Fish Shellfish Immunol. 2009;27:175-80

81. Liu Y, Rzeszutek E, van der Voort M, Wu CH, Thoen E, Skaar I, et al. Diversity of aquatic Pseudomonas species and their activity against the fish pathogenic oomycete Saprolegnia. PLoS One. 2015;10:e0136241.

82. Pallen MJ. The human microbiome and host-pathogen interactions. New York: Metagenomics of the Human Body: Springer; 2011. p. 43-61.

83. Escudeiro P, Pothier J, Dionisio F, Nogueira T. Antibiotic resistance gene diversity and virulence gene diversity are correlated in human gut and environmental microbiomes. mSphere. 2019:4:e00135-19.

84. Gerzova L, Videnska P, Faldynova M, Sedlar K, Provaznik I, Cizek A, et al. Characterization of microbiota composition and presence of selected antibiotic resistance genes in carriage water of ornamental fish. PLoS One. 2014:9:e103865

85. Moran GP, Coleman DC, Sullivan DJ. Comparative genomics and the evolution of pathogenicity in human pathogenic fungi. Eukaryot Cell. 2011; 10:34-42.

86. Thongkao K, Sudjaroen Y. Beta-lactamase and integron-associated antibiotic resistance genes of Klebsiella pneumoniae isolated from Tilapia fishes (Oreochromis niloticus). J Appl Pharm Sci. 2019;9:125-30.

87. Brahmi S, Touati A, Dunyach-Remy C, Sotto A, Pantel A, Lavigne JP. High prevalence of extended-spectrum $\beta$-lactamase-producing Enterobacteriaceae in wild fish from the Mediterranean Sea in Algeria. Microb Drug Resist. 2018; 24:290-8.

88. Del Rio-Rodriguez RE, Inglis V, Millar SD. Survival of Escherichia coli in the intestine of fish. Aquac Res. 1997;28:257-64.

89. Chen F, Sun J, Han Z, Yang X, Xian JA, Lv A, et al. Isolation, identification and characteristics of Aeromonas veronii from diseased Crucian carp (Carassius auratus gibelio). Front Microbiol. 2019;10:2742.

90. Jiang Y, Xie C, Yang G, Gong X, Chen X, Xu L, Bao B. Cellulase-producing bacteria of Aeromonas are dominant and indigenous in the gut of Ctenopharyngodon idellus (Valenciennes). Aquac Res. 2011;42:499-505.

91. Dong HT, Techatanakitarnan C, Jindakittikul P, Thaiprayoon A, Taengphu S, Charoensapsri W, et al. Aeromonas jandaei and Aeromonas veronii caused disease and mortality in Nile tilapia, Oreochromis niloticus (L.). J Fish Dis. 2017;40:1395-403.

92. Tetlock A, Yost CK, Stavrinides J, Manzon RG. Changes in the gut microbiome of the sea lamprey during metamorphosis. Appl Environ Microbiol. 2012;78:7638-44.

93. Mackie TJ, Arkwright JA, Pyrce-Tannatt TE, Mottram JC, Johnston WD, Menzies WJ. Interim report of the furunculosis committee. Edinburgh: His Majesty's Stationery Office; 1930. p. 65.

94. Teng L, Deng L, Dong X, Wei S, Li J, Li N, et al. Genome sequence of hypervirulent Aeromonas hydrophila strain HZAUAH. Genome Announc. 2017;5:e00012-7.

95. Ringø $E$, Jutfelt $F$, Kanapathippillai $P$, Bakken $Y$, Sundell K, Glette J, et al. Damaging effect of the fish pathogen Aeromonas salmonicida ssp. salmonicida on intestinal enterocytes of Atlantic salmon (Salmo salar L.). Cell Tissue Res. 2004;318:305-11.
96. Deodhar LP, Saraswathi K, Varudkar A. Aeromonas spp. and their association with human diarrheal disease. J Clin Microbiol. 1991;29:853-6.

97. Agger WA, McCormick JD, Gurwith MJ. Clinical and microbiological features of Aeromonas hydrophila-associated diarrhea. J Clin Microbiol. 1985;21:909-13.

98. Tomás JM. The main Aeromonas pathogenic factors. ISRN Microbiol. 2012; 2012:256261.

99. Sugita H, Nakamura T, Tanaka K, Deguchi Y. Identification of Aeromonas species isolated from freshwater fish with the microplate hybridization method. Appl Environ Microbiol. 1994;60:3036-8.

100. Velayudhan J, Jones MA, Barrow PA, Kelly DJ. L-serine catabolism via an oxygen-labile L-serine dehydratase is essential for colonization of the avian gut by Campylobacter jejuni. Infect Immun. 2004;72:260-8.

101. Gómez GD, Balcázar JL. A review on the interactions between gut microbiota and innate immunity of fish. FEMS Immunol Med Microbiol. 2008:52:145-54.

102. Austin B. The bacterial microflora of fish, revised. ScientificWorldJournal. 2006:6:931-45.

103. Tan CK, Natrah I, Suyub IB, Edward MJ, Kaman N, Samsudin AA. Comparative study of gut microbiota in wild and captive Malaysian Mahseer (Tor tambroides). Microbiologyopen. 2019:8:e00734.

104. Tsuchiya C, Sakata T, Sugita H. Novel ecological niche of Cetobacterium somerae, an anaerobic bacterium in the intestinal tracts of freshwater fish. Lett Appl Microbiol. 2008;46:43-8.

105. FastQC Babraham Bioinformatics; version 0.11.7. 2018. https://www. bioinformatics.babraham.ac.uk/projects/fastqc. Accessed 12 Jan 2018.

106. Picard Broad Institute. 2018. https://github.com/broadinstitute/picard. Accessed 20 Jan 2018.

107. Segata N, Waldron L, Ballarini A, Narasimhan V, Jousson O, Huttenhower C. Metagenomic microbial community profiling using unique clade-specific marker genes. Nat Methods. 2012;9:811-4.

108. Walsh AM, Crispie F, O'Sullivan O, Finnegan L, Claesson MJ, Cotter PD. Species classifier choice is a key consideration when analysing lowcomplexity food microbiome data. Microbiome. 2018;6:50.

109. Evans C, Hardin J, Stoebel DM. Selecting between-sample RNA-Seq normalization methods from the perspective of their assumptions. Brief Bioinform. 2018;19:776-92.

110. Huson DH, Beier S, Flade I, Górska A, El-Hadidi M, Mitra S, et al. MEGAN community edition-interactive exploration and analysis of large-scale microbiome sequencing data. PLoS Comput Biol. 2016;12:e1004957.

111. Singh NK, Wood JM, Karouia F, Venkateswaran K. Succession and persistence of microbial communities and antimicrobial resistance genes associated with International Space Station environmental surfaces. Microbiome. 2018;6:204

112. Huson DH, Albrecht B, Bağcı C, Bessarab I, Górska A, Jolic D, et al. MEGANLR: new algorithms allow accurate binning and easy interactive exploration of metagenomic long reads and contigs. Biol Direct. 2018;13:6.

113. Huerta-Cepas J, Szklarczyk D, Forslund K, Cook H, Heller D, Walter MC, et al. eggNOG 4.5: a hierarchical orthology framework with improved functional annotations for eukaryotic, prokaryotic and viral sequences. Nucleic Acids Res. 2015:44:D286-93.

114. Kanehisa M, Goto S. KEGG: Kyoto encyclopedia of genes and genomes. Nucleic Acids Res. 2000;28:27-30.

115. Overbeek R, Olson R, Pusch GD, Olsen GJ, Davis JJ, Disz T, et al. The SEED and the rapid annotation of microbial genomes using subsystems technology (RAST). Nucleic Acids Res. 2014;42:D206-14.

116. Peng Y, Leung HC, Yiu SM, Chin FY. IDBA-UD: a de novo assembler for single-cell and metagenomic sequencing data with highly uneven depth. Bioinformatics. 2012;28:1420-8.

117. Rho M, Tang H, Ye Y. FragGeneScan: predicting genes in short and errorprone reads. Nucleic Acids Res. 2010;38:e191.

118. Chen L, Yang J, Yu J, Yao Z, Sun L, Shen Y, et al. VFDB: a reference database for bacterial virulence factors. Nucleic Acids Res. 2005;33:D325-8.

119. Victors Virulence Factors. 2018. http://www.phidias.us/victors/. Accessed 20 Jul 2018.

120. Marti E, Huerta B, Rodríguez-Mozaz S, Barceló D, Marcé R, Balcázar JL. Abundance of antibiotic resistance genes and bacterial community composition in wild freshwater fish species. Chemosphere. 2018;196:115-9.

121. Jia B, Raphenya AR, Alcock B, Waglechner N, Guo P, Tsang KK, et al. CARD 2017: expansion and model-centric curation of the comprehensive antibiotic resistance database. Nucleic Acids Res. 2017;45:D566-73. 
122. Yarygin $\mathrm{K}$, Tyakht A, Larin A, Kostryukova E, Kolchenko S, Bitner V, et al. Abundance profiling of specific gene groups using precomputed gut metagenomes yields novel biological hypotheses. PLoS One. 2017;12: e0176154.

123. Li H. Aligning sequence reads, clone sequences and assembly contigs with BWA-MEM. arXiv preprint arXiv:1303.3997. 2013.

124. Kang DD, Froula J, Egan R, Wang Z. MetaBAT, an efficient tool for accurately reconstructing single genomes from complex microbial communities. PeerJ. 2015;3:e1165.

125. Parks DH, Imelfort M, Skennerton CT, Hugenholtz P, Tyson GW. CheckM: assessing the quality of microbial genomes recovered from isolates, single cells, and metagenomes. Genome Res. 2015;25:1043-55.

126. Aziz RK, Bartels D, Best AA, DeJongh M, Disz T, Edwards RA, et al. The RAST server: rapid annotations using subsystems technology. BMC Genomics. 2008:9:75.

127. National Center for Biotechnology Information. 2018. https://www.ncbi.nlm. nih.gov/genome/?term=Aeromonas. Accessed 25 Oct 2018.

128. Contreras-Moreira B, Vinuesa P. GET_HOMOLOGUES, a versatile software package for scalable and robust microbial pangenome analysis. Appl Environ Microbiol. 2013;79:7696-701.

\section{Publisher's Note}

Springer Nature remains neutral with regard to jurisdictional claims in published maps and institutional affiliations.

Ready to submit your research? Choose BMC and benefit from:

- fast, convenient online submission

- thorough peer review by experienced researchers in your field

- rapid publication on acceptance

- support for research data, including large and complex data types

- gold Open Access which fosters wider collaboration and increased citations

- maximum visibility for your research: over $100 \mathrm{M}$ website views per year

At BMC, research is always in progress.

Learn more biomedcentral.com/submissions 